\title{
'Contemporary Classicism' Copy of a Copy: Appropriating Classical Statues as Conceptual Readymades
}

\author{
Hallie G. Meredith \& Sarah E. Barnett
}

\begin{abstract}
Conceptual readymades - a contemporary artist's use of a classical work selected as a key point of reference taken out of time - have developed in recent years as part of contemporary art's appropriation of Greco-Roman statuary. This investigation argues that a contemporary artist's use of the classical does not represent 'copies' but cultural readymades. Contemporary digital and sculptural work foregrounding the classical sheds light on the parallel phenomenon whereby Roman reinterpretations of Greek sculpture may have been equivalent to contemporary classicism. Contemporary case studies featuring digital media, generative art, and sculpture are approached both from the perspective of what they can reveal about contemporary art's use of the classical and what contemporary art's use of classical sculpture can suggest about Roman reinterpretations as cultural readymades. Remade as part of contemporary art, classical sculpture is uniquely positioned as an accessible point of reference with which to comment on our own time by concurrently reframing the past.
\end{abstract}

Keywords Léo Caillard, conceptual readymade, contemporary classical, copy, Kopienkritik, Egor Kraft, original, Francesco Vezzoli

\section{Introduction}

For contemporary visual artists engaging with 'the classical', the continued relevance of antiquity lies in its re-making. Reinterpreting visual culture is integral to contemporary discourse. ${ }^{1}$ For example, Duchamp's concept of the readymade is premised on the idea that a pre-existing object is promoted to contemporary art. His famous Fountain illustrates the underlying notion that the readymade is a manufactured

\footnotetext{
* We wish to thank Washington State University for support and resources provided by a 2020 Research Fellowship, and to Léo Caillard for an interview as well as Egor Kraft for gratis images. We are especially grateful to Bente Kiilerich, Astri Karine Lundgren, Dan Manwaring and Michael F. Thomas, and to the reviewers.

${ }^{1}$ On time, see in particular Kubler 1965; Settis 2006; Nagel 2012; Powell 2012; Karlholm \& Moxey 2018; Tamm \& Olivier 2019.
} 
object. $^{2}$ Today, contemporary artists combine three ideas fundamental to the readymade; these are: (1) creative selection, (2) transformation of classical sculpture into contemporary art, and (3) engaging with and instilling new meaning. The same phenomenon appears to underlie the use of a tacit conceptual readymade developed in recent years as part of contemporary art's appropriation of Greco-Roman statuary. As extant classical sculptures appear today, they are typically larger than life-sized figures chiselled out of bleached white marble with little or no traces of polychromy. Pottery has also been chosen to serve as a conceptual readymade in contemporary art. In other words, a conceptual readymade is a contemporary artist's use of a classical work selected as a key point of reference taken out of time. As such and to varying degrees, a recognisable classical piece is invoked, deconstructed and reframed as a means of commenting on the present.

The impulse to engage with and reinterpret referents symbolising the past, showing intersections and convergence with present-day concerns, is, in part, inherent in the classical sculpture selected by contemporary artists. Today, 'modern Classicisms' to borrow Bente Kiilerich's term, is a phenomenon of the early twenty-first century in which 'renowned antique statues have served as points of departure for the creation of new works' in contemporary sculpture. ${ }^{3}$ These contemporary versions of GrecoRoman works recall debates concerning Roman 'copies' of Greek 'originals'. In a parallel phenomenon from the classical past that may have been equivalent to modern Classicisms, Roman artisans reinterpreted Greek sculpture as a cultural readymade. ${ }^{4}$ As such, it was part of contemporaneous visual expression. For example, Roman Emperor Augustus's forum in Rome includes smaller scale versions of caryatids from the south porch of the Erechtheion on the Athenian Acropolis. The specific choice to include 'exact copies, in reduced scale' as part of his forum in Rome whilst simultaneously funding a restoration of the then four-hundred-year-old structure highlights the political nature of this replicative choice. ${ }^{5}$ A century later in Emperor Hadrian's gardens in his villa at Tivoli, Egyptian, Greek and Roman sculptures were 'copied' and new pieces were commissioned. ${ }^{6}$ Two features shared by these examples of imperial Roman remaking are (1) the reproduction of a version of a caryatid, suggesting the same cultural referent, and (2) the selection of this replicated sculpture as part of an architectural complex and place of display. ${ }^{7}$ In sum, an ancient reference

\footnotetext{
${ }^{2}$ Tate (inv. no. T07573), London. Anonymous Editorial edited by Duchamp and two colleagues, The Blind Man, May 1917. Cf. Seitz \& Shattuck 1961.

${ }^{3}$ Kiilerich 2019, 103-113. For definitions of 'the classical', see 103-104. On the process of classicism as central to the transmission and transformation of Graeco-Roman art, see especially Trimble \& Elsner April 2006, 209; Marvin 2008, especially 121-247; Vout 2018, 15-36. For a model of interconnectedness, see Pitts \& Versluys (eds) 2015.

${ }^{4}$ On key issues concerning Kopienkritik, with bibliography, see Trimble \& Elsner 2006, 201-12.

${ }^{5}$ Kleiner 1992, 100, fig. 83.

${ }^{6}$ The caryatids at Hadrian's Villa at Tivoli may once have decorated Agrippa's Pantheon. Cf. Pensabene \& Antonelli 2012, 1331-1337; Ojeda 2021, 391-417.

${ }^{7}$ See Plantzos 2017, 3-29.
} 
was incorporated as a remade physical statue integrated into a (then) present-day structure as a means of engaging with the past in the viewer's present. Likewise, explicit references to antiquity in contemporary art point to a wider practice of concurrent appropriation and iconoclasm as part of the remaking of classical referents as a mode of expression. Fundamental to the expressive recasting of the classical today is the underlying notion of a temporal division.

Whereas academics create a linear sense of time in order to create a temporal distance separating the past from the present, the material presence of visual culture prompts reinterpretation in the present. ${ }^{8}$ Laurent Olivier argues that archaeology's understanding of time is 'memory recorded in matter'. 'Adopting this approach to time, the ways in which remnants from the past are reinserted and reframed in the present not only revise our understanding of the past but also our understanding of the present. Olivier states, '[m]aterial things embed themselves in all subsequent presents....Thus, even though the Roman Empire collapsed for good in times which are completely over and done with, its material remains nonetheless continue to occupy our present'. ${ }^{10}$ Subjectivities and cultural perspectives are, therefore, intertwined with knowledge of the classical past and our understanding of it through remaking. The contemporary context, therefore, is where ideas about the past are conceived. The focus of this study is contemporary art's use of the classical as a conceptual readymade to critique the present. The goal of curation is often implicit in contemporary uses of ancient cultural references, and in such public presentations conservation and choreography can intertwine. Choreography is also fundamental to exceptional displays of the inverse aim of destruction, where instead a challenge is made to present-day assumptions concerning the value of preserving artefacts not only as cultural referents but as intrinsically imprinted objects of the past. ${ }^{11}$

The political force of destroying an irreplaceable vestige from the past 'embedded in our subsequent present' can be profound. Regardless of the cultural tradition, a cultural readymade from the ancient past can have a powerful political impact on contemporary society. For example, Chinese artist Ai Weiwei (b. 1954) was perhaps the first artist to use the phrase 'cultural readymade' with reference to his controversial performance, Dropping a Han Dynasty Urn (1995) implying a critique of cultural value systems. ${ }^{12}$ This performative work entailed destroying a two millenniaold ceremonial urn from the Han dynasty (206 BCE - $220 \mathrm{CE})$, a defining period in

\footnotetext{
${ }^{8}$ Hingley 2015, 32-46, 35.

${ }^{9}$ Olivier 2004, 204-213, especially 204. See also Tamm \& Olivier 2019.

10 Olivier 2004, 206.

11 Of course there may be many other possible goals and nuances between curation and annihilation, such as an inaccessible 'original', destruction highlighting the value to preserve artefacts, provoking questions about the value, or the opposite, of classical objects through these appropriations.

12 On parallel, collective experiences, see Marks 2010, especially 1-5.
} 
the history of Chinese civilisation. ${ }^{13}$ The provocative piece invoked a Han dynasty urn as a cultural readymade in a contemporary comment on China's Cultural Revolution (1966-76) prompting debates over what constitutes desecration and value today. ${ }^{14}$ The destruction of the artefact unambiguously foregrounded its 1995 reception as the product of subsequent historic events. An artefact alone, however, is not a cultural readymade. Nor is a cultural readymade synonymous with an original. A salient difference is the significance attributed to the original as a cultural referent. Ai Weiwei's destructive act was shocking. Changed into a metonymic symbol, this destructive act demands that viewers question the meaning ascribed to the ancient object today. This reaction stems from the destruction of a protected and desirable symbol of value, a cultural artefact transformed into an icon from a crucial point in time. The original as icon is at the core of what constitutes a cultural readymade. Could such debates echo those in the ancient Roman period?

Demonstrating continuities with imperial Rome, today visual references to earlier esteemed traditions often take the form of reinterpretations as remade but largely intact bodies. A critical feature shared by contemporary artists working with classical sculpture is the integration of identifiable and largely complete versions of statuary. ${ }^{15}$ The recognisability of references to intact versions of the classical past is a salient feature inherent in modern Classicisms. In short, early twenty-first-century visual artists are appropriating classical statues as conceptual readymades questioning what defines contemporary encounters with the past as integral to their investigations.

As an appropriated symbol representing a distant time and place of production and (initial) reception, such references help create the perception of a division in linear time between a distant past and the viewer's present mediated by the contemporary artist reframing the classical. ${ }^{16}$ In contemporary classicisms, visual culture as classical

\footnotetext{
13 Guggenheim, Bilbao, accessed 20 November 2021, https://thenewartfest.art.blog/2020/01/01/ai-weiwei/, and more recent works like Han Dynasty Vases with Auto Paint (2014).

${ }^{14}$ Similarly, in what is believed to have been a comment on greed in international art markets, although not using an historic work, in 2018 the anonymous artist Banksy staged a surreptitious performance at a public auction house in London. Immediately after the public sale of Girl with a Red Balloon (c. 2005) a device built into the frame partially shredding his own painting. Banksy renamed the partially shredded piece Love is in the Bin (2018) as a means of taking credit for a shocking public act of destruction and the creation of a new work, accessed 20November 2021, https://www.sothebys.com/en/articles/sothebys-gets-banksyed-at-contemporary-art-auction-inlondon.

${ }^{15}$ For example, working with historic figures, although not classical sculpture, American artist Deborah Oropallo (b. 1954) creates layered, historical-style portraits. Oropallo superimposes historic portraits, principally of powerful men from the seventeenth and eighteenth centuries, with erotic images of women For instance, see Oropallo's Napoleon (2001) from the series Guise, accessed 20 November 2021, https://cclarkgallery.com/artists/series/deborahoropallo/Guise $\% 20$ Series.

16 See the references in note 1. On frames and framing, see Derrida 1978, 19-168; Lebensztejn 1988; Kiilerich 2001; Platt \& Squire (eds) 2017.
} 
referent is generally treated in one of two ways. First as a concept, in the sense that through digital means a recreated version references and serves as a (distinguishable) substitute for an original. For example, this occurs in digitally rendered emulations of classical sculpture (Figs. 1-4). Akin to a conceptual vestige, as a proxy altered digital representations of classical statues highlight disjunctions between contemporary practice and ancient figural instantiations. Alternatively, a second possibility is that a conceptual readymade object is maintained as a relic, in the sense that it is irreplaceable and venerated as such. ${ }^{17}$ For example, genuine classical statues are incorporated into contemporary art as artefacts. As instantiations of the conceptual readymade, whereas the former type of contemporary classicism underscores the conceptual representation, the latter highlights the physicality of the remnant displayed in the viewer's presence. Together, both illustrate differentiable facets of appropriation and iconoclasm in cultural readymades as part of contemporary classicisms. Reciprocally, and akin to the Kopienkritik debate, as concept or relic conceptual readymades have the potential to further elucidate and even enhance our understanding of the classical past by reshaping our perceptions of it in the present. Additionally, what can artificial intelligence (i.e. AI-generated art) suggest concerning how we approach concepts such as 'original' and 'copy'?

This investigation argues that a contemporary artist's use of the classical does not represent 'copies' but cultural readymades. Contemporary digital and sculpture foregrounding the classical includes emblematic work, for instance, by Léo Caillard, Egor Kraft and Francesco Vezzoli, which sheds light on the parallel phenomenon whereby Roman reinterpretations of Greek sculpture may have been equivalent to contemporary classicism. Caillard and Vezzoli each have a growing body of work centred around contemporary art's appropriation and engagement with iconic western statuary. Moreover, Caillard, Vezzoli and Kraft are worthy of special attention here because each employs a different approach to 'the classical' as fluid, malleable and dynamic in its reformulation in the present.

In these contemporary case studies involving appropriative and iconoclastic references to the classical past, that antecedent is invoked as a point of reference. The focus, however, lies in the viewer's experience of the present. Focusing on select contemporary case studies, this work first considers altered reproductions of classical statues before turning to classical sculpture demonstrating use of the classical as a cultural readymade commenting on the present. Next, the role of authentic classical sculpture in AI-generated art is considered. Case studies are approached both from the perspective of what they can reveal about contemporary art's use of the classical and what contemporary art's use of classical sculpture can suggest about Roman reinterpretations as cultural readymades.

17 On Duchamp's readymades prompting reflection of the relic, Nagel 2011, especially 216-217; cf. Nagel 2012, 228-240. 


\section{Contemporary art's appropriation and iconoclastic acts re-producing relics}

Remaking is not the same as copying. ${ }^{18}$ In a classic work on replication contextualising Kopienkritik with iterations from the early twenty-first century, Jennifer Trimble and Jaś Elsner define replication as comprised of two parts. The first part is visual, where artefacts and images function metonymically. The second is more subjective, involving historic socio-political circumstances, in the mind and in its social network of relations'. ${ }^{19}$ Thereby, a combined sign and signified determine viewer experience. Addressing viewer reception and the reciprocal nature of remaking as self-definition, they argue that 'every replication is an ideological decision to combine, categorise, mediate and reinterpret form, intersecting with contemporary culture and society in powerful wayss ${ }^{20}$ Inherent and central to remaking, therefore, is the use of conceptual readymades reframed for an audience today.

Contemporary Classicisms highlight interplay between cross-temporal disjunctions. Concurrently appropriative and iconoclastic, core cultural referents establish a tension that not only calls attention to but punctuates the universality of present-day concerns. There are also specific instances when contemporary remaking seeks to call into question our understanding of established cultural references by concurrently invoking and challenging them. ${ }^{21}$ For example, Vezzoli creates a chimeric figure by placing the head of a third-century C.E. Roman imperial portrait on a version of the body of the 'Woman from Willendorf' statuette. However, it is in the act of naming where Vezzoli reverses the referent to the contemporary, as the 2018 piece is called Portrait of Kim Kardashian (Ante Litteram). ${ }^{22}$ It is thus iconoclastic both toward the present and the past.

In dissimilar ways, two twenty-first-century artists in particular have the shared aim of employing classical sculpture as a conceptual readymade. This investigation first considers contemporary artists altering reproductions of ancient statues by examining the work of artist Léo Caillard, specifically the use of modern clothing on digitally reproduced classical sculpture. Second, turning to contemporary artist's altering ancient sculpture itself, we consider Francesco Vezzoli's juxtapositions of reproduced classical sculpture in dialogue with the artist's self-portraits. Both artists simultaneously invoke the classical as part of a wider practice prompting reflection on

\footnotetext{
${ }^{18}$ On Roman copies, in German known as Kopienkritik, see Trimble \& Elsner 2006, 201-212 with previous scholarship. For distinctions between replicas, copies, repetitions, series and multiples see Cupperi 2014, 7-28; Settis 2015, 51-72, especially 69. See also: Anguissola 2015, 73-80.

${ }^{19}$ Trimble \& Elsner 2006, 202. Cf. Davis 1996, 1.

20 Trimble \& Elsner 2006, 209.

${ }^{21}$ The power of artefacts as relics is, in large part, fundamental to experiencing relics in person, and the display of reliquaries as a precursor to the modern art museum. See Nagel 2011, 211-22; Gahtan \& Pegezzano 2014; Bartal et al. 2017; Adornato et al. 2020.

${ }^{22}$ See Seymour, 2021, fig. 8. On kitsch, see the classic work by Greenberg 1939, 34-49. The question is worth asking whether this piece would qualify as 'kitsch', and the difference between kitsch and iconoclasm. On kitsch and emulation, see Binkley 2000, especially 142-8; Ortlieb \& Carbon 2019, 1-17.
} 


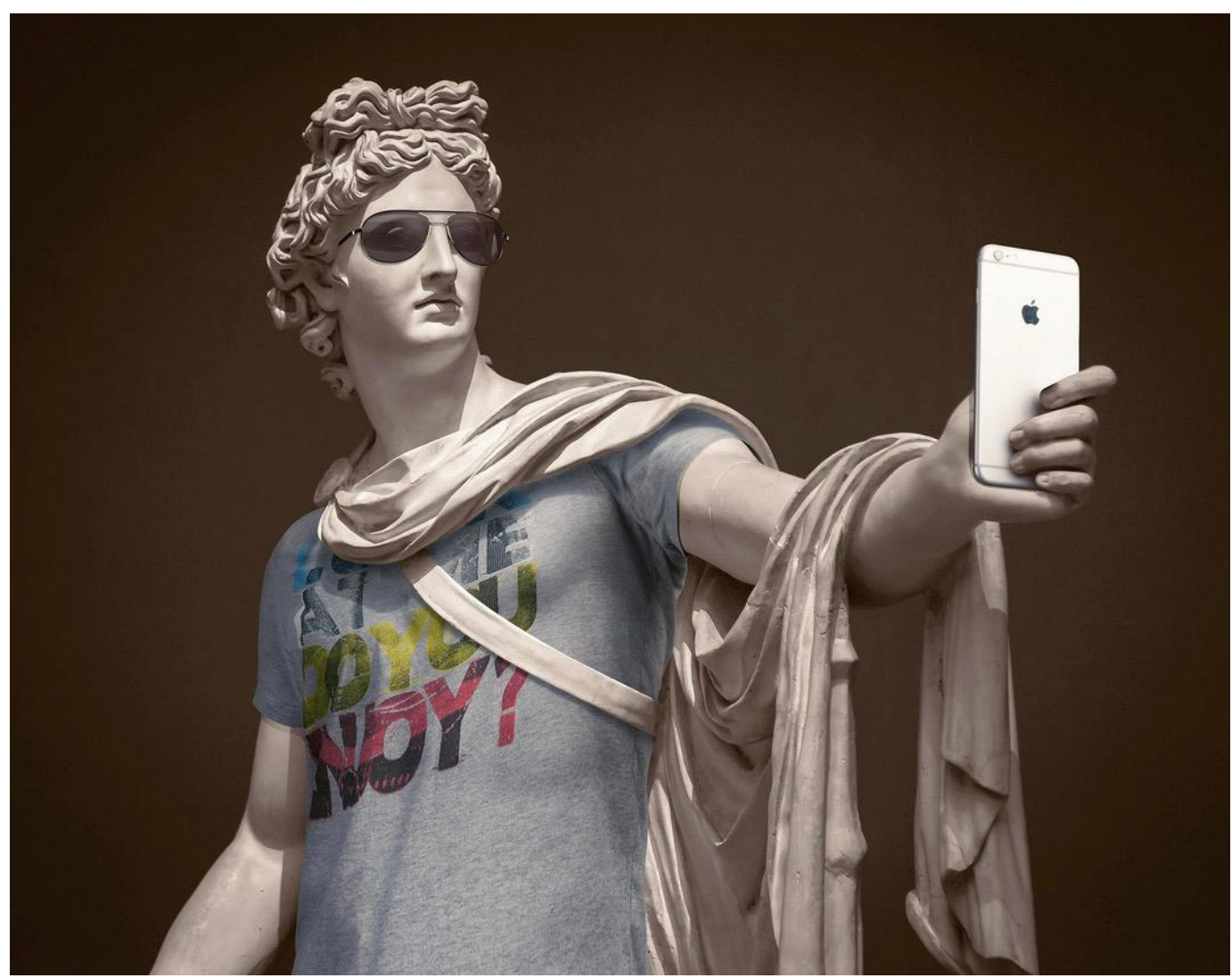

Fig. 1 Léo Caillard, Hipsters in Stone III, 2017. Photography: digital, https://www.leocaillard.com/artworks.html

the present. According to the artists that comprise the core examples, the past is not the focus. As conceptual readymades, classical sculpture serves as recognisable referents. As such, they are a means of pointing to the universality or continuities with similar concerns (such as the self/selfie) in the past.

\section{Contemporary artist's altering reproductions of classical sculpture}

Classical sculpture is one of two core cultural referents in French artist Léo Caillard's (b. 1985) appropriative reproductions; the other is dress, a contemporary marker of identity. Caillard's Hipsters in Stone I-III (2012-2017) presents digitally manipulated versions of classical marble statues in contemporary dress. ${ }^{23}$ Among the sculpture chosen are representations of Roman versions of Greek sculpture - reinterpretations of reinterpretations! Reproduced statues wear, for example, chequered shirts, shirts with holes, logos and accessories (such as sunglasses, bracelets and wristwatches), or

23 Pers. comm. 14 May 2021; Léo Caillard's website, accessed 20 November 2021, https://www.leocaillard.com/artworks.html; Squire et al. 2018, 112-122. 


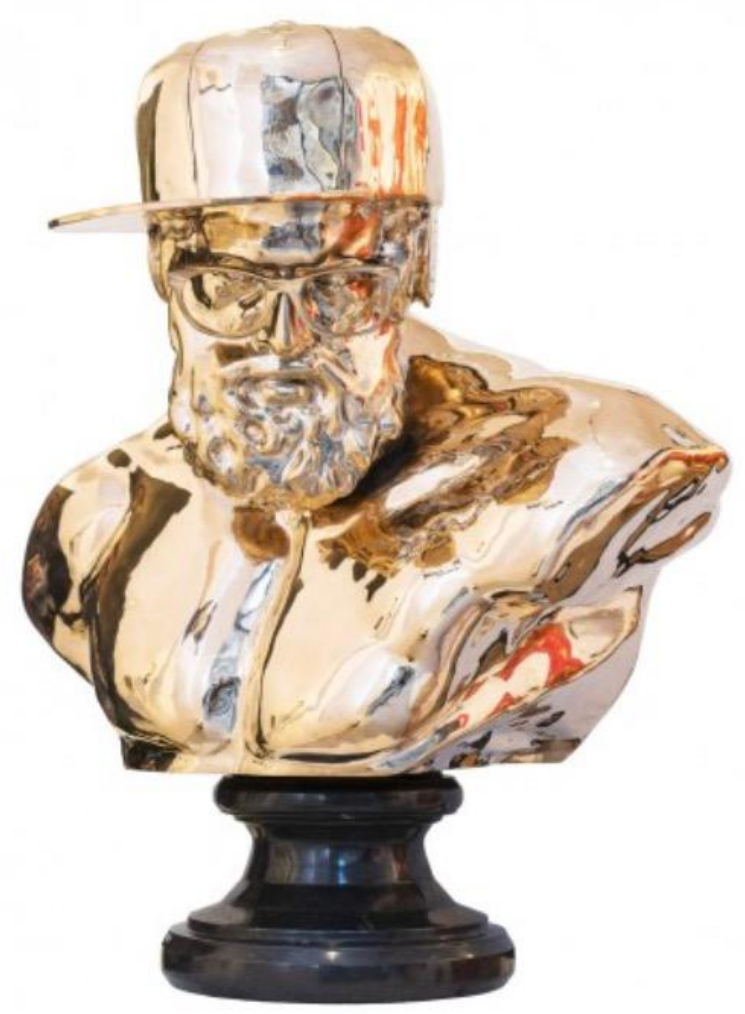

Fig. 2 Léo Caillard, Hipsters in Bronze I, 2015, bronze bust, $80 \mathrm{~cm}$. Photography: https://www.leocaillard.com/artworks.html

they might even hold a mobile phone while posing for a selfie (Fig. 1). Similarly, bronze busts from Hipster in Bronze I (2016) wear accessories such as sunglasses, headphones and hats (Fig. 2). In Light Stone (2017), Caillard presents a resin marble version of the Discobolus, for example, sculpted in laser light and neon (Fig. 3). Further contributing to the conceptual readymade physicalised in the form of a classical marble sculpture now devoid of polychromy is Caillard's creation of both haptic three-dimensional, physical statues (Hipsters in Bronze I, Light Stone) and intangible photographs existing in digital form (Hipsters in Stone I-III). ${ }^{24}$ Whereas reproduced classical figures allude to the universal concerns of these idealised bodies in frozen postures devoid of their original contexts of display, Caillard brings the sculpted forms in direct alignment with viewers today by layering digital representations of the classical with contemporary dress and accessories.

\footnotetext{
24 On ancient polychromy and sculpture, see: Abbe 2008, 136-51; Primavesi 2007, 192-209;
} Brinkmann et al. 2017. 


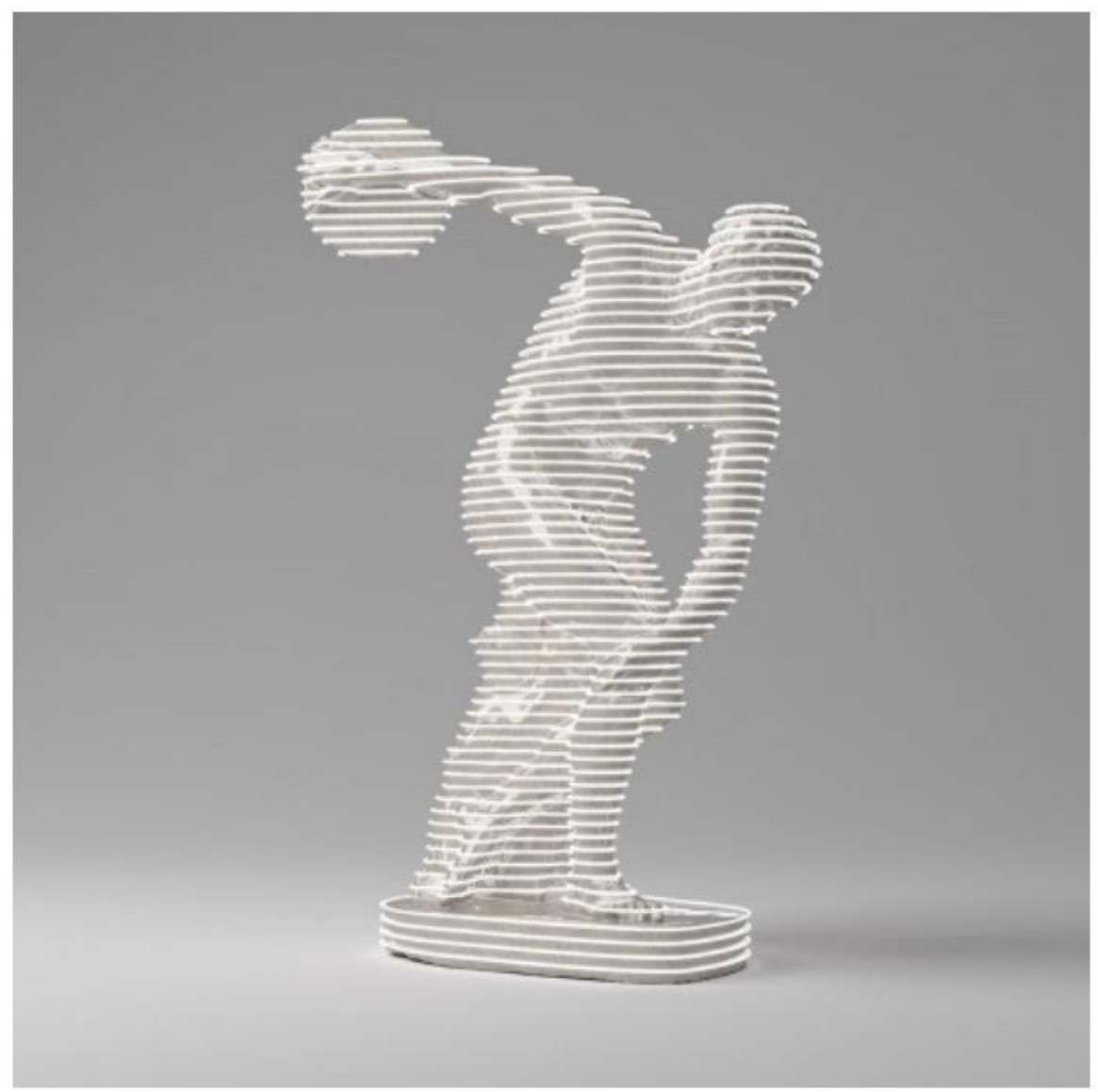

Fig. 3 Léo Caillard, Light Stone, 2017, marble and neon sculpture, $205 \mathrm{~cm}$. Photography: https://www.leocaillard.com/artworks.html

This resonance with spectators enables them to see the classical as a metaphoric mirror reflecting their own everyday concerns. Clothes function as the index or sample of a specific history, the documents of their time. ${ }^{25}$ In contrast to the timelessness of ideal nude bodies, the addition of clothes delimits the socially defined person to a specific time and place. ${ }^{26}$ Moreover, the choice of typical contemporary dress highlights the disjunction between well-known classical sculpture and the quotidian. Thereby, Caillard is encouraging viewers today to approach the visual quotations in his work as part of the wider aims underlying the work as a whole. Furthermore, these motivations were surely similar in some ways to those inherent in Roman artists' reinterpretations of ancient Greek sculpture for contemporaneous viewers. As cultural readymades,

${ }^{25}$ Nagel 2011, 215-216.

${ }^{26}$ See Squire et al. 2018, 116-118. 


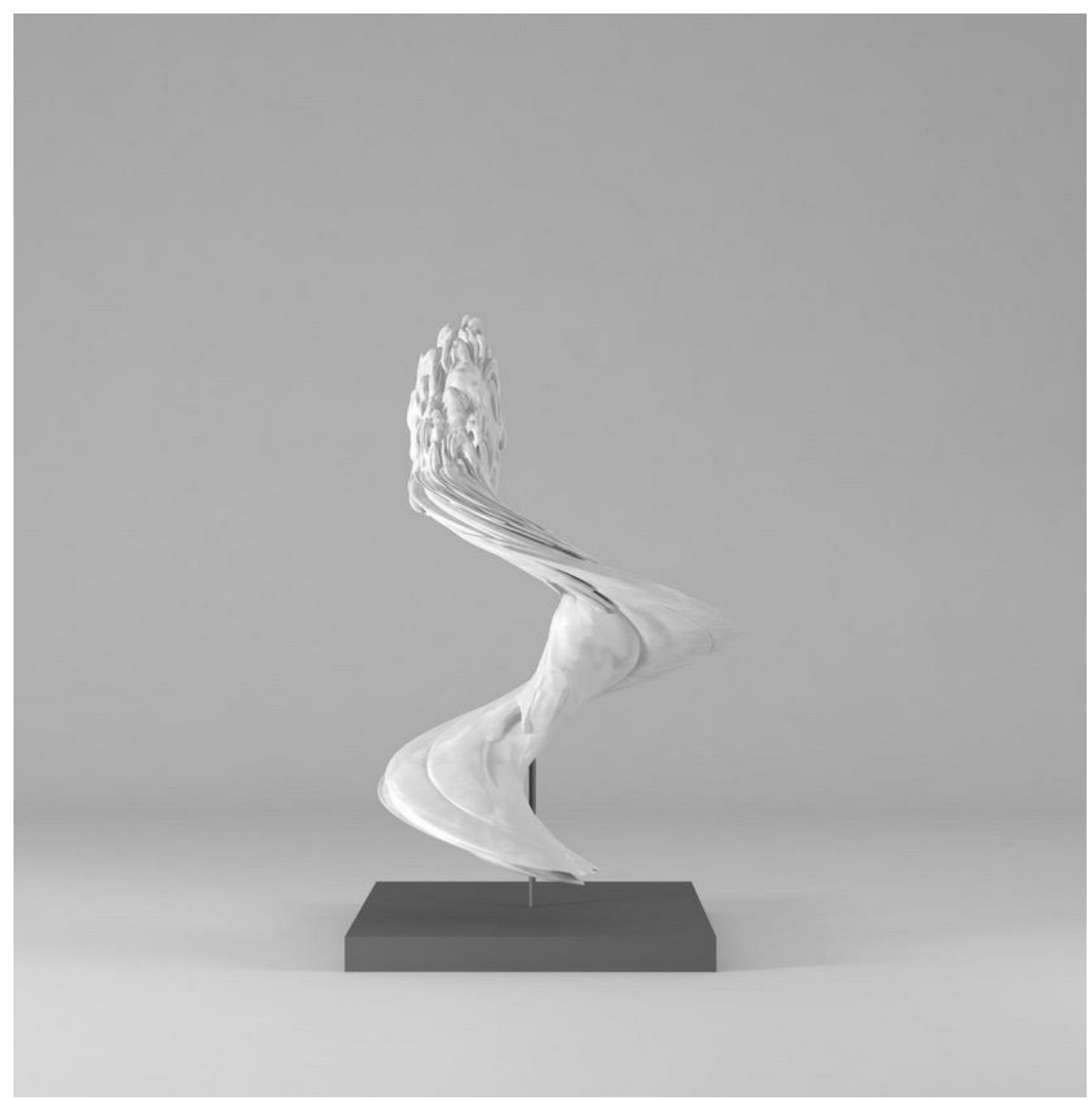

Fig. 4 Léo Caillard, Wave Stone, 2017, marble sculpture, $70 \mathrm{~cm}$. Photography: https://www.leocaillard.com/artworks.html

digitally recreated versions of classical sculpture function as conceptual proxies referencing 'originals' as part of a critique on contemporary society.

The reinterpretations of classical sculpture discussed preserve a version of the original that is recognisable due to the preservation and retention of the entire figure. In contrast, in W ave Stone (2017), Caillard distorts classical sculpture rendered digitally, preserving the identifiable face but deforming the body (Fig. 4). Unlike Caillard's alterations to the meticulously reproduced classical statue's form by photogrammetry, VR, or other digital means, contemporary artists working with genuine classical sculpture as a relic or fragment of a whole are taking a comparatively material approach to cultural readymades. 


\section{Contemporary artist's altering actual classical sculpture}

A format that Italian artist Francesco Vezzoli (b. 1971) uses to encourage viewers to approach the classical and contemporary as separated by a temporal expanse, yet connected and in conversation, is a side-by-side format juxtaposing a version of a classical sculpture with a bust of the artist. ${ }^{27}$ Serving as an explicit catalyst, the implicit comparison between what are two independent busts are presented as parts of a whole. ${ }^{28}$ Visually presented as though in dialogue, the choice of a self-portrait responding provocatively (e.g. with a kiss or sticking his tongue out) to the represented classical statue models behaviour for contemporary viewers. ${ }^{29}$ Playing with the artist's identity, Vezzoli recasts Apollo's expression as part of a conversation in the viewer's presence in Self-portrait as Apollo del Belvedere's Lover (2011). ${ }^{30}$ The title reframes the focus, inviting viewers to reinterpret what lies behind the exchange. Contexts of display are vital to the comparative nature of this work, perhaps as important as the content. Vezzoli's work is positioned in and among three galleries collections that include work by Donatello, Verrocchio, Sebastiano del Piombo and Diego Velazquez, 'an exercise in artistic camouflage'. ${ }^{31}$ It is this explicit comparative approach that is central to Vezzoli's work in particular, the means by which viewers are challenged to reinterpret an implicit past/present comparison as a duality, highlighting difference and representing universals at the same time. Moreover, while referencing homosexuality among males in antiquity, ${ }^{32}$ the title guides the viewer to reimagine these busts as an intimate conversation focusing not only on the artist's sexuality but also his cultural legacy.

Vezzoli is well-known for work that transgresses boundaries between contemporary visual art, cultural heritage, restoration and access. A subsequent piece in dialogue with ancient Roman artefacts is part of a wider conversation, not only about his country but more broadly about 'the classical restored' in the viewers' presence. In collaboration with classical archaeologists and conservators, Vezzoli's Teatro Romano 2014-2015 exhibition at MoMA PS1 featured five real first- and second-

\footnotetext{
27 On Vezzoli's signature tear added as a visualised mark of the artist, contrasting 'ancient masters' and contemporary Italian artists, see: Yang Lan 2014; Perrella (ed.) 2016. Recently, see Vezzoli's exhibition in Brescia, Summer 2021.

28 Tay 2014, 1.

29 Obtaining copyright to reproduce Vezzoli's images was problematic. See, for example, Vezzoli's Satyr of a Satyr, 2011, marble, Rennie Collection, Vancouver, see Needham 2016, fig. 5; Ricciardi 2016. On Vezzoli’s 2011 Self-Portrait as Apollo del Belvedere's Lover, marble, Fondazione Prada, Milan, see: ‘Opening Francesco Vezzoli, Museo Museion,' 29 January 2016, accessed 7 December 2021, https://www.museion.it/2016/01/opening-francesco-vezzoli-museomuseion/?lang=en, fig. 1 .

30 See n. 29.

31 Tay 12 June 2014, 1.

32 See, for example, Clarke 2013, 509-533.
} 
century CE Roman busts that were painted replicating their original polychromy. ${ }^{33}$ Questioned about this work, Vezzoli has underscored the political nature of 'the classical' for Italians in particular. Addressing his use of real ancient Roman sculpture in Italy today, Vezzoli states, '[o]ur cultural heritage seems to be the biggest global asset we have...it's also a comment on how Italy has little left but its past'. ${ }^{34}$ Moreover, it is striking that this work highlights the care taken to responsibly restore, as closely as possible, the original painted colours. ${ }^{35}$ One of Vezzoli's stated aims is to 'reeducate our understanding of what classicality means' ${ }^{36}$ An illustration of this point is the controversy caused by the intentional destruction of antiquity. Whether framed as a spectacle of destruction ${ }^{37}$ or as a performance, ${ }^{38}$ such politically-motivated iconoclastic acts are antithetical to the core goal of preservation inherent in practices from reliquaries to modern art museums.

We have considered contemporary artists' engagement with classical sculpture by producing singular works based on extant material and in response to present-day concerns. These contemporary acts of remaking make explicit the classical referents employed as cultural readymades in a dynamic representation of genuine classical sculpture. Caillard's work integrates classical cultural readymades as conceptually appropriative and iconoclastic in contrast to Vezzoli's approach to classical cultural readymades as physical relics. Neither artist's work is a slavish copy of an original eschewing interpretation. Instead, each artist has responded to the past invoked, in material form, with a unique work of their own. Artificial intelligence-generated work offers an opportunity to investigate what might at first glance appear to be a copy of a copy.

\section{A unique copy}

The iterative basis of art generated by algorithms has not been investigated with respect to cultural readymades as proxies or relics. Debates concerning AI-driven art have centred on questions concerning human-machine collaborative creations, ${ }^{39}$ whether machine intelligence is a form of creativity, ${ }^{40}$ and its value as a form of expression. ${ }^{41}$ Fundamental to these issues and to those inherent in late nineteenth-

\footnotetext{
33 'Francesco Vezzoli: Teatro Romano Oct 26, 2014-Mar 9, 2015 MoMA PS1', 2014, accessed 7 December 2021, https://www.moma.org/calendar/exhibitions/3735, figs. 1 and 2; Swanson 2014, fig. 1. Cf. Tay 2014; Marconi 2016, 348-354.

34 Swanson 2014, 2.

35 Although the composition of the pigments used were not reported, this is an important field in classical archaeology.

36 Swanson 2014, 2.

37 For example, Harmansah 2015.

38 Gamboni 2010, 82-95.

${ }^{39}$ Coeckelbergh 2017; Kurt 2018; Daniele \& Yi-Zhe Song 2019.

40 Boden 2004; Miller 2019. Cf. Zylinska 2020, especially 49-56.

41 The topic of the value of AI in contemporary art is the subject of another paper and will not be addressed here.
} 
century Kopienkritik debates is the premise that replication is 'an act empty of any subjectivity', focusing almost exclusively on the 'originals to which copies were meant to give access', with Roman artisans considered equivalent to 'replicators' ${ }^{42}$ Faithful reproductions directly replicating cultural referents have not only been popular for centuries, such remade work also transforms a recognisable point of cultural reference into the 'original'. Multiples referencing a unique referent transform the singular, in this way reaching the status of symbolic icon.

Replicative technologies have served to exponentially increase the myriad copies of copies. From eighteenth-century plaster casts ${ }^{43}$ to twenty-first-century 3D prints, the means of replication have become more sophisticated..$^{44} 1956$ was the first use of the term 'Artificial Intelligence'; ${ }^{45}$ however, visual art has 'always been technical'. ${ }^{46}$ The Louvre's Nike of Samothrace is a well-known example. In 1863, this statue was found with a fragmentary right wing and pieces missing. As part of the statue's reconstruction, a copy was made of the extant wing. ${ }^{47}$ The right wing is, therefore, a literal copy designed to make the statue appear sufficiently complete to viewers. Today, classical archaeologists work with 3D models to address issues concerning cultural heritage or input thousands of examples of classical material (such as inscriptions) to 'train' computers to fill gaps, for example in missing inscriptions to aid reconstructions. ${ }^{48}$ The goal remains a search for a lost original.

AI-generated visual art offers not only a contemporary counterpoint to the works of Caillard and Vezzoli but also to Roman reinterpretations of Greek sculpture. Although the goals governing computer-aided archaeological restorations and AIdriven visual art differ, both use technology that appears to be virtually indistinguishable. Considering twenty-first-century versions of classical art based on large datasets of genuine ancient sculpture generated as algorithms, how can art in the age of novel mechanical reproduction ${ }^{49}$ shed light on contemporary art's cultural readymades, as well as ancient Roman interpretations of Greek statuary? To address this question, we first consider Egor Kraft's Content Aware Series (2019) before addressing the implications of these AI-generated iterations as classical cultural readymades.

42 Trimble \& Elsner 2006, 203.

43 See, for example, Frederiksen (ed.) 2010.

44 Münster et al. 2018.

45 On the origins of AI see Ting Guo 2015. Cf. Brown (ed.) 2020.

46 Zylinska's emphasis, 2020, 13.

47 See: Ridgway 2000, 150-157, fig. 48.

48 See, for example, Digital Classicist, https://www.digitalclassicist.org/; Digital History, https://ihrdighist.blogs.sas.ac.uk/; European Association for Digital Humanities, https://eadh.org/. On cultural heritage, for instance, Benardou et al. 2017. On inscriptions, see Tupman 2020, https:/ / youtu.be/sVUg9R1315E.

49 Benjamin 1969, 217-251. Cf. Zylinska 2020, 65-73. 


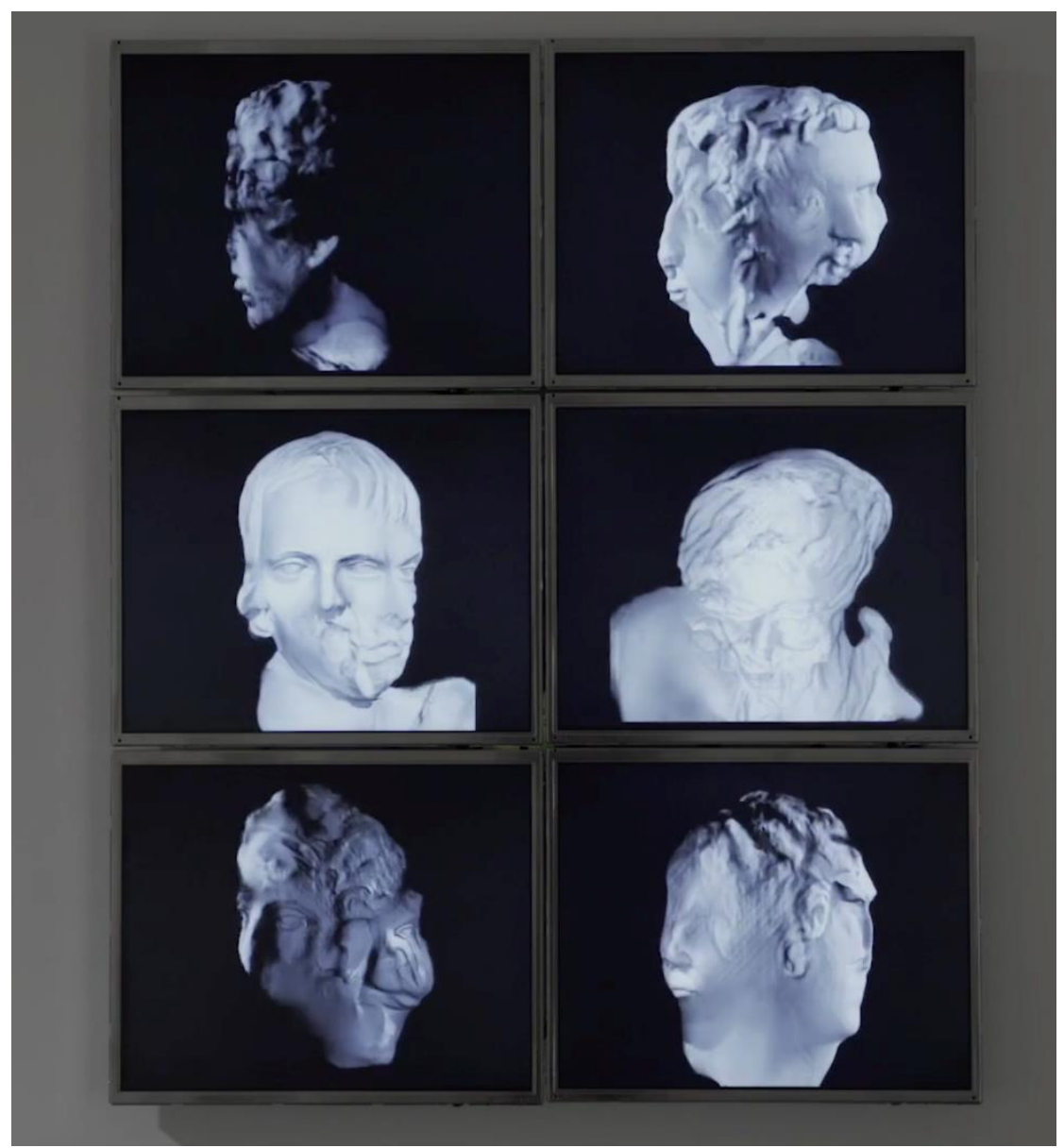

Fig. 5 Egor Kraft, detail of Content Aware Studies, 2018; 6 channel video installation; Machine learning algorithms, custom dataset. Alexander Levy Gallery, Berlin. Photography: Egor Kraft, with permission.

In stark contrast to classical sculpture remade by ancient Roman artists or contemporary counterparts Caillard and Vezzoli, the work of Russian artist Egor Kraft (b. 1986) offers an example of AI-generated art highlighting a process to generate multiples, instead of a single authoritative piece. Authenticity, authorship, and materiality are central to Kraft's 2019 Content Aware Studies multi-channel video installation with 3D printed polyamide and marble sculpture. ${ }^{50}$ Representing a widespread practice among AI artists, Kraft worked with a data scientist to train artificial neural networks. ${ }^{51}$ The algorithm generates computer models which are then

\footnotetext{
${ }^{50}$ Kraft 2020, 7-30.

${ }^{51}$ Kraft 2020, 7; Zylinska 2020, 75-86. See also AI artists such as Memo Akten, Mario Klingemann and Anna Ridler.
} 


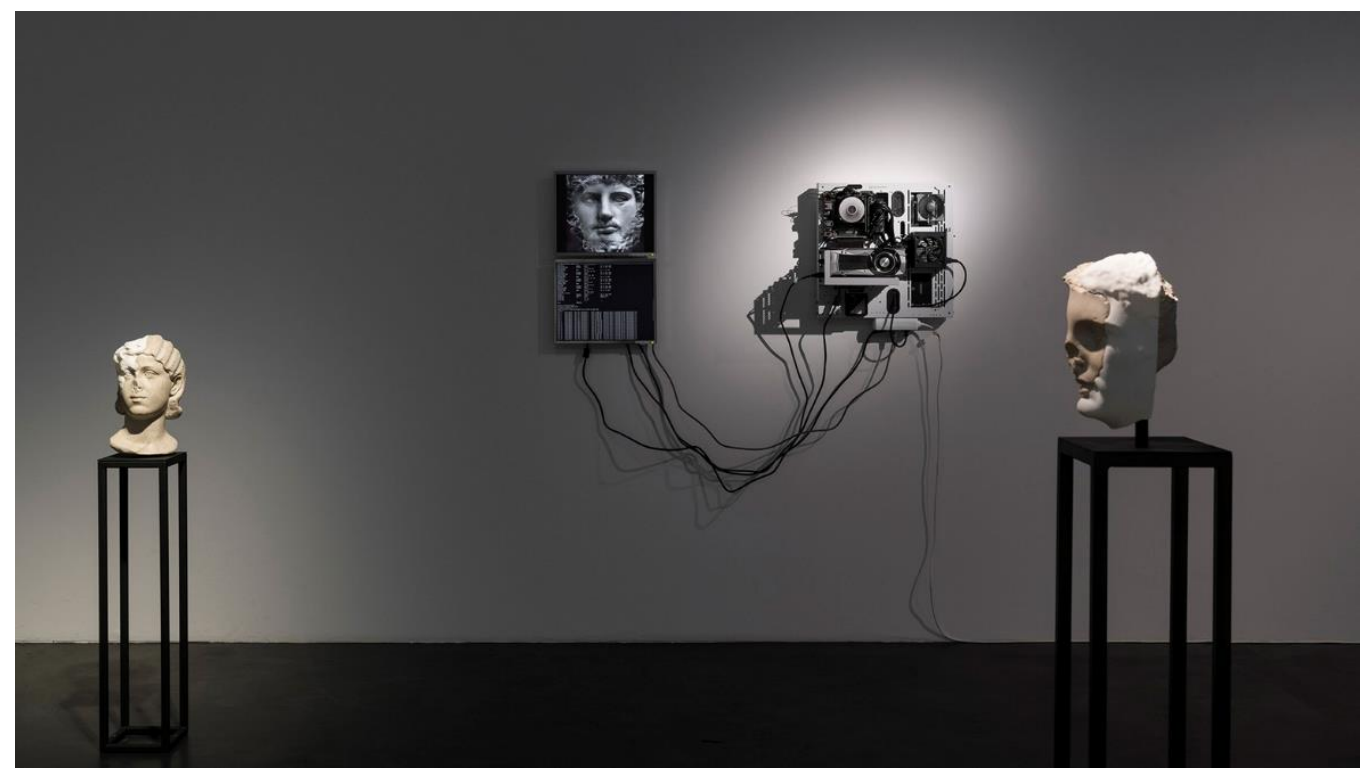

Fig. 6 Egor Kraft, Content Aware Studies, installation view, 2018, Alexander Levy Gallery, Berlin. Photography: Trevor Good, with permission.

3D printed in synthetic materials (Figs. 5-6). Kraft says the process 'replenishes lost fragments of sculptures and friezes of classical antiquity and generates never before existing, yet authentic objects of that era ${ }^{52}$ His interests lie in the process of machine vision rather than in the accuracy of the results. In short, instead of using classical sculpture to generate faithful reproductions, AI is employed with the goal of producing novel variations.

Despite the absence of a direct human creator, in deciding the aim of the images generated (i.e. as patterned after and quantifiably similar to but distinct from their classical models) Kraft choreographs what the algorithms produce. Elements of Content Aware Series echo Caillard's Wave Stone (Fig. 4) and Vezzoli's Teatro Romano. Paired with a video illustrating an AI-produced series of distorted portraits that never existed morphing into one another, Kraft selects the variants that are paired with classical marble sculpture. However, unlike Caillard or Vezzoli's use of classical readymades, in his engagement with classical sculpture, Kraft's AI-generated visual art is relative. Kraft does not specify why a particular generated piece is selected in preference to another to complement an incomplete classical sculpture. There is no implicit hierarchy or an end point, nor is one piece more finished than another. Zylinska argues that recognition as visual art 'supersedes the analysis of the art object as a singular entity with a supposedly timeless value. ${ }^{53} \mathrm{~A}$ machine-generated piece

\footnotetext{
52 Kraft 2020, 7.

53 Zylinska 2020, 15.
} 
does not appear to be the missing piece but rather one of myriad possibilities unseen before, a choice not made.

Although AI-generated art may initially appear to regurgitate copies of copies, a more nuanced understanding of this synthesis of the classical and contemporary as algorithm suggests the work produced is a novel form of a copy. It is novel in that the remade images are often not found among the originals but instead based on vast permutations. The work generated is, therefore, not limited to slavish copies but rather seemingly endless, equally unexpressed, choices not made. ${ }^{54}$ In other words, Kraft's enquiry into classical statues central to Content Aware Studies is as alternative possibilities that never existed. ${ }^{55}$

Since multiple permutations are all equally likely and unlikely, there is no discernible critique inherent in this work, no commentary concerning the source material and no commentary concerning the present viewer. By contrast, classical statues, whether incomplete due to lack of funds or for other reasons, have a single authoritative version. ${ }^{56}$ Authority is understood in two senses. First, in the sense that the visible form is final. Serving as a reinterpretation, this version is not one among many equally potential iterations, but instead it has been selected from among many. Second, the work is authoritative in the sense that a singular work represents the artist's decision concerning what constitutes resolution to a problem under consideration and is evident in the work's completeness. ${ }^{57} \mathrm{It}$ is this definitive archetype that is invoked in subsequent remakings and precisely what transforms subsequent iterations into alternative interpretations.

Contemporary artists working with AI to generate variants, plausibly reversing the tacit presumption inherent in the Kopienkritik debate, raises parallel questions concerning not only authenticity and authorship but also intentionality. Egor Kraft's use of classical sculpture as conceptual readymades produced by AI was not restricted to the final form of the work produced and whether it was a slavish copy. Highlighting process, there is an explicit divide between the methodological replication of thousands of authentic statues used to 'train' a computer (i.e. copies of originals), and novel algorithmically-generated sculptures that never existed (i.e. unique in that the non-hierarchic possibilities never existed). The result of this process appears to be 'unique copies' as a kind of cultural readymade that reference and are based on classical works yet are novel.

\footnotetext{
${ }^{54}$ On choices not made and the chaine opératoire (operational sequence), see Leroi-Gourhan 19641965; van der Leeuw 1993, 238-288; Meredith, under review.

55 On AI-generated faces, see also Trevor Paglen 2016; Wang 2018.

${ }^{56}$ On an author function, Foucault 1992, 299-314, especially 306. Zylinska defines this with respect to AI art as 'a wider discursive arrangement that stabilizes into what a given cultural moment perceives as an 'author' or 'artist' 2020, 15.

${ }^{57}$ Marchand 2016.
} 


\section{Conclusion}

For contemporary visual artists engaging with 'the classical', the continued relevance of antiquity lies in the goals underlying its remaking. Nineteenth-century ideas concerning Roman copies of Greek originals were criticised for failing to consider the aims inherent in so-called copies. As contemporary reinterpretations of classical sculpture have demonstrated, the purposes for which classical sculptures were chosen are crucial to their revised roles in contemporary visual discourse.

Contemporary artists engaging with classical sculpture as a key point of reference taken out of time are doing so in at least three ways: as appropriative and iconoclastic; as a relic; and as part of a non-hierarchic process. As conceptual readymades, recognisable classical sculpture is invoked, deconstructed and reframed as a means of commenting on the past, the present and time itself. First, as a substitute referencing a recognisable 'original', as in the work of Léo Caillard, conceptual readymades are a means of pointing to the universality or continuities with similar concerns (such as the self/selfie) in the past. Functioning as conceptual proxies, they reference an antecedent as part of a critique on contemporary society. Second, as a relic of an original, as in the work of Francesco Vezzoli, the viewer is guided to reconceive new pairings or new additions as a dialogue about cultural heritage, preservation and destruction. Third, as an ongoing process of generating permutations, as in the work of Egor Kraft, the fundamental opposition between nonhierarchic generative works and classical sculpture's definitive form underscores the need for an authoritative form for subsequent remakings. As myriad permutations demonstrate, an explicit final form is essential to transform subsequent iterations into alternative interpretations. Contemporary artists' use of the classical does not represent 'copies' but cultural readymades - i.e. classical work selected as a key point of reference taken out of time and reconceived for the present, or, in the example of AI-directed digital art, made for the first time. Remade as part of contemporary art, classical sculpture is uniquely positioned as an accessible point of reference with which to comment on our own time by concurrently reframing the past.

Associate professor Hallie G. Meredith

Washington State University

hallie.meredith@lincoln.oxon.org

Master of Fine Arts Candidate Sarah E. Barnett

Washington State University

sarahbarnettart@gmail.com 


\section{References}

Abbe, M. B. 2008: 'Polychromy and Gilding on Marble Statuary at Aphrodisias', in R. R. R. Smith \& J. Lenaghan (eds), Roman Portraits from Aphrodisias, 136-151. Istanbul: Yainlari.

Adornato, G., Cirucci, C. \& Cupperi, W. 2020: Beyond 'Art Collections': Owning and Accumulating Objects from Greek. Antiquity to the Early Modern Period. Berlin: De Gruyter.

Anguissola, A. 2015: 'Masterpieces and Their Copies: The Greek Canon and Roman Beholders', in S. Settis \& A. Anguissola (eds), Serial / Portable Classic: The Greek Canon and Its Mutations, 73-80. Milan: Fondazione Prada.

Barandoni, C. 2019: 'Mann-in-Colours. The First Italian Database on Polychromy of Ancient Sculptures', Proceedings of the 23rd International Conference on Cultural Heritage and New Technologies 2018, 23 (2019): 1-6.

Bartal, R., Bodner, N. \& Kuhnel, B. (eds) 2017: Natural Materials of the Holy Land and the Visual Translation of Place, 500-1500. London: Routledge.

Benardou, A., Champion, E., Dallas, C. \& Hughes, L. M. (eds) 2017: Cultural Heritage Infrastructures in Digital Humanities. London: Routledge.

Benjamin, W. 1969: The Work of Art in the Age of Mechanical Reproduction. Transl. H. Zohn, in Illuminations, H. Arendt (ed.), 217-251. New York: Schochen Books.

Binkley, S. 2000: 'Kitsch as a Repetitive System: A Problem for the Theory of Taste Hierarchy', Journal of Material Culture 5(2): 131-152.

Boden, M. A. 2004: The Creative Mind: Myths and Mechanisms. $2^{\text {nd }}$ edition. London \& New York: Routledge.

Brinkmann, V. (ed.) 2017: Gods in Color: Polychromy in the Ancient World. Munich: Prestel.

Brown, K. (ed.) 2020: The Routledge Companion to Digital Humanities and Art History. New York: Routledge.

Clarke, J. R. 2013: 'Sexuality and Visual Representation', in Th. K. Hubbard (ed.), $A$ Companion to Greek and Roman Sexualities, 509-533. Malden: Wiley.

Coeckelbergh, M. 2017: 'Can Machines Create Art?', Philos. Technol. 30(3): 285-303. 
Cupperi, W. 2014: 'Never Identical. Multiples in Pre-Modern Art?', in W. Cupperi (ed.), Multiples in Pre-Modern Art, 7-28. Zurich: Diaphanes.

Daniele, A \& Song, Y.-Z. 2019: 'AI + Art = Human', in AAAI/ACM Conference on AI, Ethics, and Society (AIES '19), January 27-28, 2019, Honolulu, HI, USA (2019): 155161.

Davis, W. 1996: Replications: Archaeology, Art History, Psychoanalysis. University Park: Pennsylvania State University Press.

Derrida, J. 1978: 'Parergon', 19-168, in La Vérité en Peinture. Paris: Flammarion.

Foucault, M. 1992: 'What Is an Author?', in J. D. Caputo, M. Westphal \& J. L. Marsh (eds), Modernity and Its Discontents, 299-314. New York: Fordham University Press.

Frederiksen, R. (ed.) 2010: Plaster Casts: Making, Collecting and Displaying from Classical Antiquity to the Present. Berlin: De Gruyter.

Gahtan, M. W. \& Pegezzano, D. 2014: Museum Archetypes and Collecting in the Ancient World. Leiden: Brill.

Gamboni, D. 2010: 'Portrait of the Artist as an Iconoclast', in G. Moore, R. Torchia, P. Tinari \& G. Adamson (eds), Ai Weiwei: Dropping the Urn: Ceramic Works, 5000 BCE-2010 CE, 82-95. Glenside: Arcadia University Art Gallery.

Greenberg, C. 1939: 'Avant-garde and Kitsch', Paris Review 6: 34-49.

Guo, T. 2015: 'Alan Turing: Artificial Intelligence as Human SelfKnowledge', Anthropology Today 31(6): 3-7.

Harmansah, Ö. 2015: 'Isis, Heritage, and the Spectacles of Destruction in the Global Media’, NEA 78(3): 170-177.

Hingley, R. 2015: 'Post-Colonial and Global Rome: The Genealogy of Empire', in M. Pitts \& M. J. Versluys (eds), Globalisation and the Roman World: World History, Connectivity and Material Culture, 32-46. Cambridge: Cambridge University Press.

Karlholm, D. \& Moxey K. (eds) 2018: Time in the History of Art: Temporality, Chronology and Anachrony. New York: Routledge. 
Kiilerich, B. 2001: 'Savedoff, Frames, and Parergonality', Journal of Aesthetics and Art Criticism 59(3): 320-323.

Kiilerich, B. 2019: 'The Classical in Contemporary Sculpture: A Global View', Proceedings of the Danish Institute at Athens 9: 103-113.

Kleiner, D. E. E. 1992: Roman Sculpture. New Haven: Yale University Press.

Kraft, E. 2020: Content Aware Studies Series, September 2020, 7-30, accessed 20 November 2021.

Kubler, G. 1965: The Shape of Time: Remarks on the History of Things. New Haven: Yale University Press.

Kurt, D. E. 2018: 'Artistic Creativity in Artificial Intelligence', PhD diss. Nijmegen: Radboud University.

Lan, Y. 2014: 'Historical Links', in Global Times, Gagosian Gallery (17 December 2014).

Lebensztejn, J.-C. 1988: 'Framing Classical Space’, ArtJ 47(1): 37-41.

Leroi-Gourhan, A. 1964-1965: Le geste et la parole, vol. 2. Paris: Albin Michel.

Marchand, T. H. J. (ed.) 2016: Craftwork as Problem Solving: Ethnographic Studies of Design and Making. Farnham: Ashgate.

Marconi, C. 2016: 'Teatro Romano', in C. Perrella (ed.), Francesco Vezzoli, 348-354. New York: Rizzoli.

Marks, L. U. 2010: Enfoldment and Infinity: An Islamic Genealogy of New Media Art.

Cambridge, MA.: MIT Press.

Marvin, M. 2008: The Language of the Muses: The Dialogue between Roman and Greek Sculpture. Los Angeles: J. Paul Getty Museum.

Meredith, H. under review: 'The Unfinished Chaîne Opératoire: A New Approach to Unseen Late Roman Choices'.

Miller, A. I. 2019: The Artist in the Machine: The World of AI-Powered Creativity. Cambridge, MA.: MIT Press. 
Münster, S, Friedrichs, K. \& Hegel, W. 2018: '3D Reconstruction Techniques as a Cultural Shift?’, International Journal for Digital Art History 3(3): 38-59.

Nagel, A. 2011: 'The Afterlife of the Reliquary', in M. Bagnoli, H. A. Klein, C. G. Mann \& J. Robinson (eds), Treasures of Heaven: Saints, Relics and Devotion in Medieval Europe, 211-222. London: British Museum Press.

Nagel, A. 2012: Medieval Modern: Art out of Time. New York: Thames \& Hudson.

Needham, A. 2016: 'The Artist Francesco Vezzoli on the Ancient World, Celebrity and "Mrs Prada", The Guardian (4 January 2016).

Ojeda, D. 2021: 'Fragments of Roman Sculptures from Hadrian's Villa', AJA 125 (3): 391-417.

Olivier, L. 2004: 'The Past in the Present. Archaeology, Memory and Time', Archaeological Dialogues 10(2): 204-213.

Ortlieb, Stefan A. \& Carbon, C.-C. 2019: 'A Functional Model of Kitsch and Art: Linking Aesthetic Appreciation to the Dynamics of Social Motivation', Frontiers in Psychology 9: 2437, $1-17$.

Paglen, T. 2016: 'Invisible Images (Your Pictures Are Looking at You)', The New Inquiry (8 December 2016), https://thenewinquiry.com/invisible-images-yourpictures-are-looking-at-you/;

Pensabene, P. \& Antonelli, F. 2012: 'Provenance of Marble Sculptures and Artifacts from the So-Called Canopus and Other Buildings of "Villa Adriana" (Hadrian's Villa e Tivoli, Italy)', JAS 39(5): 1331-1337.

Perrella, C. (ed.) 2016: Francesco Vezzoli. New York: Rizzoli.

Pitts, M. \& Versluys, M. J. (eds) 2015: Globalisation and the Roman World. World History, Connectivity and Material Culture. Cambridge: Cambridge University Press.

Plantzos, D. 2017: 'Caryatids Lost and Regained: Rebranding the Classical Body in Contemporary Greece', Journal of Greek Media \& Culture 3 (2017): 3-29.

Platt, V. \& Squire, M. J. (eds) 2017: The Frame in Classical Art: A Cultural History. Cambridge: Cambridge University Press. 
Powell, A. K. 2012: Depositions: Scenes from the Late Medieval Church and the Modern Museum. Cambridge, MA.: MIT Press.

Primavesi, O. 2007: 'Colorful Sculptures in Ancient Literature? The Textual Evidence Revisited', in V. Brinkmann, W. Hornbostel \& R. Wünsche (eds), Bunte Götter: die Farbigkeit antiker Skulptur, 192-209. Hamburg: Museum für Kunst und Gewerbe.

Ricciardi, N. 2016: 'Review Francesco Vezzoli, Museion Bozen/Bolzano, Italy', Frieze (12 February 2016).

Ridgway, B. S. 2000: Hellenistic Sculpture II: The Styles of ca. 200-100 B.C. Madison: University of Wisconsin Press, 2000.

Seitz, W. C. \& Shattuck, R. 1967: Art of Assemblage Symposium, October 19, 1961. New York: Museum of Modern Art.

Settis, S. 2006: The Future of the "Classical", transl. A. Cameron. Cambridge: Polity Press.

Settis, S. 2015: 'Supremely Original: Classical Art as Serial, Iterative, Portable', in S. Settis \& A. Anguissola (eds), Serial / Portable Classic: The Greek Canon and Its Mutations, 51-72. Milan: Fondazione Prada.

Seymour, H. 2021: 'The Unpredictable Art of Francesco Vezzoli: Spectacle, Sex, Celebrity -and Antiquity' (1 October 2021), https://www.christies.com/features/Interview-with-artist-Francesco-Vezzoli11794-1.aspx

Squire, M., Cahill, J. \& Allen, R. 2018: 'Interview with Léo Caillard', in M. Squire, J. Cahill, J. \& R. Allen (eds), The Classical Now, 112-122. London: Elephant Art.

Swanson, C. 2014: 'The Cut, Francesco Vezzoli Paints up Ancient Roman Busts', Gagosian Gallery (28 October 2014).

Tamm, M. \& Olivier, L. (eds) 2019: Rethinking Historical Time: New Approaches to Presentism. London: Bloomsbury Academic.

Tay, M. 2014: 'Francesco Vezzoli to Exhibit at Pitti Uomo', in Blouin Artinfo, Gagosian Gallery (12 June 2014). 
Trimble, J. \& Elsner, J. 2006: 'Introduction: 'If You Need an Actual Statue . . ', Art History 29(2): 201-212.

Tupman, C. 2020: 'Reconsidering the Roman Workshop: Applying Machine Learning to the Study of Inscribing Texts', Digital Classicist London Seminar 2020, Institute of Classical Studies, https://youtu.be/sVUg9R1315E

Van der Leeuw, S. E. 1993: 'Giving the Potter a Choice: Conceptual Aspects of Pottery Techniques', in P. Lemonnier (ed.), Technological Choices: Transformation in Material Cultures since the Neolithic, 238-288. London: Routledge.

Vout, C. 2018: 'The Error of Roman Aesthetics', in B. Dufallo (ed.), Roman Error: Classical Reception and the Problem of Rome's Flaws, 15-36. Oxford: Oxford University Press.

Wang, P. 2018: 'This Person Does Not Exist', (accessed 20 November 2021), https://thispersondoesnotexist.com/.

Zylinska, J. 2020: AI Art: Machine Visions and Warped Dreams. London: Open Humanities Press. 